transitions in solids first discussed by Peierls in 1932 have by no means been fully developed.

Perhaps the most substantial developments of the ast few years have taken place in the understanding of phosphorescence processes in solids and their association in many instances with the existence of electron traps in the phosphor. A semi-quantitative theory of trap processes, which fits the facts as well as may be expected at this stage, is now available; it has also been shown in a clear way that the release of electrons from traps results in changes of dielectric constant. While the mechanism of some luminescence processes in impurity solids is now reasonably well understood, the nature of electron traps is almost completely unknown. It may be expected during the next few years that a closer study of the properties of impurity phosphors in relation to the methods of preparation, and in particular the use of fluxes, may greatly increase our knowledge of this technically important field. Knowledge of trap processes has chiefly been obtained by the investigation of the thermal release of electrons; much remains to be done in the collateral study of the optical release of electrons by infra-red absorption. Even so, photo-luminescence studies have proceeded at a greater rate than those of cathodo-luminescence, and a proper synthesis of the two fields of work has yet to be achieved.

In the volume under notice, Prof. Curie touches on a few of the aspects that have been mentioned, but the emphasis which he gives to them would, I am sure, be much altered in a later edition. The volume contains eight chapters: general theory of photoluminescence ; optical resonance and fluorescence of gases and vapours; fluorescence of complex molecules; fluorescence of solutions; inorganic phosphors; cathodo-luminescence; chemi- and bioluminescence; applications. The references in the text are to authors only, and give no indication of the source of the information or date of publication.; thirteen more general references are given at the end of the book.

J. T. RANDALL

\section{MODERN ORGANIC CHEMISTRY}

\section{Organic Chemistry}

By Prof. Paul Karrer. Translated by A. J. Mee. Third English edition, revised and enlarged. Pp. $\mathrm{xx}+$ 957. (New York and Amsterdam: Elsevier Publishing Co., Ine.; London : Cleaver-Hume Press, Ltd., 1947.) 38s. net.

7 HE success of Prof. Karrer's "Lehrbuch der organischen Chemie", which has appeared at short intervals during the past twenty years, is both a tribute to an investigator of world-wide repute and a testimony to the excellence of the book. The publication of the third English edition is therefore an event of importance.

The appearance of the book is superb. Binding, printing, and paper are enviably excellent, and special commendation must be bestowed on the quality and abundance of the graphic formulæ. In these days of hasty workmanship sueh a high standard comes as a pleasant surprise. But this surprise turns to astonishment when we note that the price is only about half that of the 1938 edition. Such reductions must be rare: in this age of rising costs unique. It is a challenging question whether a book of equal size and quality could be printed and published in Britain for the same price.
The translating and editing have been adequately done. 'Germanisms' are not noticeable, and misprints are unimportant and remarkably few for a book of this size. The spelling conforms to English custom, though biotine, tryptophane, and coramin are exceptions in this respect.

The author's statement that "every chapter has been the subject of careful scrutiny and revision" is no idle claim. Too often new editions mean little more than some titivation here and there with the addition of a few lines culled from the abstracts. Such is not the case here. No pains have been spared to include the notable advances until the end of 1945. These are inserted in the text, and the reader may rest assured that the book is thoroughly up to date. Space has been found for a great variety of subjects, including the chemistry of biotin and penicillin, the synthesis of quinine and equilenin, the nitration of the paraffins, the cobaltinitrite method for replacing the amino by the nitro group in aromatic compounds, and so on. It is therefore surprising that no mention is made of the petroleum chemical industry, surely one of the most notable recent advances, and one of more than industrial significance.

All the good things said about the first edition may confidently be said again. No one can fail to admire the orderly presentation, the lucid description of preparative methods, the emphasis on rigid determination of structure, the inclusion of many topics of biochemical interest, and the useful tables in the appendix. A notable improvement is the increased number of references to standard books and monographs (some of which are American, and a few British).

The amount of information contained in the book is tremendous. Indeed, in the reviewer's opinion, this constitutes a serious pedagogic blemish. It may seem ungracious and ungrateful to cavil at so much excellent fare; but the book, on the author's own statement, is a text-book and not a handbook. Yet one has the impression that it is a compressed 'Meyer-Jacobson', and that lucidity has been sacrificed for the sake of completeness. To take ons example: in the chapter of about fifteen pages on azo-dyes, seven are largely devoted to formulæ. It is generally accepted, of course, that a text-book must serve to some extent as a handy book of reference. In former days this was specially necessary when the alternative was the formidable volumes of Beilstein, but this no longer obtains now that data and information are readily obtained in Heilbron's "Dictionary of Organic Compounds", etc. It may also be argued that the reader can 'skip' the offending pages; but this does not get away from the fact that there is a break in the continuity of narrative, and as a result some of the chapters become heavy and indigestible. A lack of proportion also results. Two pages are devoted to vanillin; but only a part of a page (and that in small type) to the technical uses of acetylene, and little more than a page to the resonance of benzene--a section, incidentally, which is sketchy and in places misleading.

In spite of the criticism ventured above, which is a matter of opinion and in consequence debatable, 'Karrer' will appeal to research workers and others who seek authoritative information on organic chemistry. Our thanks go to the author for giving us in the middle of his voluminous contributions to the Helvetica Chimica Acta this comprehensive, up-todate survey of organic chemistry.

Neil Campbell 